\title{
Moral Incongruence and Pornography Use: \\ A Critical Review and Integration
}

\author{
Joshua B. Grubbs, Ph.D.
}

Bowling Green State University

Samuel L. Perry, Ph.D.

University of Oklahoma

Author accepted version of manuscript in press at The Journal of Sex Research.

\section{Citation:}

Grubbs, J. B. \& Perry, S. L. (In Press) Moral Incongruence and Pornography Use: A Critical Review and Integration. The Journal of Sex Research.

Correspondence regarding this manuscript should be addressed to: Joshua B. Grubbs, Department of Psychology, Bowling Green State University. Email: GrubbsJ@BGSU.edu 


\begin{abstract}
Internet pornography use (IPU) remains a controversial topic within sexual behavior research fields. Whereas some people report feeling dysregulated in their use of pornography, mental health and medical communities are divided as to whether or not IPU can be addictive. The present review seeks to examine this issue more closely, with a focus on how variables other than pornography use, such as moral disapproval and moral incongruence (i.e., feeling as if one's behaviors and one's values about those behaviors are misaligned) might specifically contribute to self-perceived problems around pornography use. Through an examination of recent literature, the present work reviews evidence that moral incongruence about IPU is a common phenomenon and that it is associated with outcomes relevant to current debates about pornography addiction. Specifically, moral incongruence regarding IPU appears to be associated with greater distress about IPU, greater psychological distress in general, greater reports of problems related to IPU, and greater reports of perceived addiction to IPU. The implications of this body of evidence for both clinical and research communities are discussed, and future directions for research are considered.
\end{abstract}

Keywords: Internet Pornography; Hypersexuality; Religion; Sexual Addiction; Morality; Dissonance 


\section{Moral Incongruence and Pornography Use:}

A Critical Review and Integration

Pornography use is an increasingly common activity in developed nations with unrestricted Internet access (Ogas \& Gaddam, 2011). Results from nationally representative samples in the U.S. indicate that up to $46 \%$ of adult men under 40 and up to $16 \%$ of adult women under 40 report using pornography in a given week (Regnerus, Gordon, \& Price, 2016). Nationally representative estimates in various other countries have found similarly high rates (e.g., (Rissel et al., 2017; Svedin, Åkerman, \& Priebe, 2011). Despite this immense popularity, Internet pornography use is also highly controversial, both in academic (Clarkson \& Kopaczewski, 2013; Ley, Prause, \& Finn, 2014) and popular (Foubert, 2016; Ley, 2016) literature. Central to these controversies are debates around the addictive (or non-addictive) nature of online pornography use, with theoretical works arguing that Internet pornography is either inherently addictive (Cooper, McLoughlin, \& Campbell, 2000; Young, 2008), mostly innocuous (Ley et al., 2014), or simply understudied (Montgomery-Graham, Kohut, Fisher, \& Campbell, 2015).

While these debates continue, there is clear evidence that some people do find their own use of pornography to be problematic (Gola, Lewczuk, \& Skorko, 2016; Kor et al., 2014) and that some individuals do report severe consequences (relationship conflict; employment difficulties; lost sleep; mental health concerns) as a result of their use (Gola \& Potenza, 2016; Kraus, Meshberg-Cohen, Martino, Quinones, \& Potenza, 2015; Ross, Månsson, \& Daneback, 2012). Moreover, internationally, increasing numbers of psychiatric and mental health professionals are encountering clientele reporting problems with IPU (Gola et al., 2016; Kraus, Martino, \& Potenza, 2016; Kraus et al., 2015; Short, Wetterneck, Bistricky, Shutter, \& Chase, 
2016). Even so, these clinical manifestations of self-perceived problematic pornography use are not entirely straightforward, as there is growing evidence that seeking treatment for selfperceived problematic pornography use may be motivated by more than the quantity or consequences of the behavior (Gola et al., 2016; Kraus et al., 2016).

The controversies regarding problematic IPU are further complicated by the morally charged nature of sexual behavior in general and pornography use specifically (Humphreys, 2017). Regardless of consequences alone, many individuals report moral disapproval of IPU, a belief that is often associated with conservative religious values (Lambe, 2004). Religious people, particularly in the Western world, tend to strongly disapprove of pornography use, but also tend to use pornography with some frequency (Grubbs, Exline, Pargament, Hook, \& Carlisle, 2015; MacInnis \& Hodson, 2015; Patterson \& Price, 2012; Perry, 2017b). In light of the controversies around IPU and the disparate literature examining the role of morality as it relates to such use, the present work seeks to review the role of morality and moral incongruence (generally, the experience of violating one's deeply held or sacred values) in predicting psychological problems associated with IPU—especially feelings of addiction to IPU—and to provide clear considerations for future clinical work and research on this topic.

\section{A Brief Note on Biases}

Before reviewing the role of moral incongruence in predicting negative outcomes of IPU, we would note that many prior works have observed that there seem to be clear biases in published literature on IPU, in that the majority of such research focuses on the potential negative outcomes of pornography use (Campbell \& Kohut, 2017; Kohut, Fisher, \& Campbell, 2017; Montgomery-Graham et al., 2015). For the present work, admittedly, our focus is similarly on potentially negative outcomes. This is not to imply — as others have done - that Internet 
pornography use is inherently or inevitably problematic or harmful, as some research does suggest potential positive outcomes associated with such use (Campbell \& Kohut, 2017; Kohut, Baer, \& Watts, 2016). However, given that the focus of the present work is on the role of moral incongruence in predicting problems associated with IPU, our work does indeed focus on negative outcomes (e.g., psychological distress, guilt, shame, feelings of addiction). Even so, as we detail below, the purpose of the present work is to offer an alternative explanation for some of these negative associations rather than concluding that such associations are inherently the result of pornography use itself.

\section{Pornography Addiction}

Pornography addiction has been discussed for many years, beginning before the general public use of the Internet (Mura, 1985; Robison, 1982; United States Attorney General's Commission, 1986). However, with the advent of the Internet and its near immediate use for the transmission of pornography (Johnson, 1996), pornography addiction became an enormously popular topic in both popular and academic circles (Cooper, 1998; Delmonico \& Carnes, 1999; Griffiths, 2000, 2001). In tandem with the rise of studies exploring purported Internet pornography addiction, a consistent — albeit much smaller_-body of literature emerged calling for more caution in Internet pornography research. Specifically, despite the influence of research describing pornography as addictive or harmful, some noted that available research regarding IPU was hardly conclusive and that it was at least as likely as not that Internet pornography was not an inherently problematic media form (Barak \& Fisher, 2002; Fisher \& Barak, 2001). Additionally, there was at least some research speculating that pornography use may have positive impacts on the lives of some individuals (Rogala \& Tydén, 2003; Weinberg, Williams, Kleiner, \& Irizarry, 2010). 
Since those early debates, research related to internet pornography use and purported addiction has grown extensively (for reviews, see: (Duffy, Dawson, \& das Nair, 2016; Gmeiner, Price, \& Worley, 2015; Ley \& Grubbs, 2017; Ley et al., 2014; Walton, Cantor, Bhullar, \& Lykins, 2017). Yet, despite this expansive growth, the debates over the addictive or nonaddictive nature of Internet pornography rage on (Ley et al., 2014; Williams, 2017). At present, there is simply no consensus within either sexual research or addiction research fields as to whether or not pornography use can be an addictive activity in and of itself. Below, we seek to examine how the morally charged nature of pornography use may further complicate this debate.

\section{Religion and Pornography}

Generally speaking, religion (broadly defined) ${ }^{1}$ often has an antagonistic or condemning view of IPU (Boulton, 2008; Sherkat \& Ellison, 1997; Thomas, 2016). Religious individuals are likely to disapprove of IPU (Grubbs, Exline, et al., 2015), support censorship of pornography (Lambe, 2004; Lykke \& Cohen, 2015), and view it as a societal problem (MacInnis \& Hodson, 2016). Religious periodicals often focus on combatting the purported vices of pornography (Thomas, 2013, 2016); religious conferences and meetings commonly attack the evils of

\footnotetext{
${ }^{1}$ In psychological literature, terms such as religiousness, religiosity, spiritual, and spirituality may refer to a variety of constructs (P. C. Hill et al., 2000; Oman, 2013; Pargament, 1999). Indeed, entire subfields within psychology more broadly are dedicated to studying the nuances of religion and spirituality and how these distinctions impact individual and social functioning (P. C. Hill et al., 2000; P. Hill \& Pargament, 2003; Pargament, 1999). Within these fields, definitions of religion or religiousness are often highly specific, with particular focus on a variety of beliefs, attitudes, and behaviors (for a review, see Hill \& Pargament, 2008). Despite these nuances, within the academic study of IPU and associated outcomes, religiousness is not often so carefully defined. As such, the majority of the studies reviewed hereafter tend to measure religiousness as some combination of religious belief salience (i.e., how important religious belief is to participants), religious participation (i.e., engagement in religious activities), and religious affiliation (i.e., faith or denominational identity).
} 
pornography (Boulton, 2008); and there is an ever-growing array of religious self-help books focused on combatting pornography addiction (Driscoll, 2009; Foubert, 2016).

Given the plethora of evidence demonstrating religious disapproval of pornography, it is, perhaps, not surprising that there is also a compelling body of research involving a variety of methods (Grubbs, Exline, et al., 2015; Hardy, Steelman, Coyne, \& Ridge, 2013; Perry, 2017d; Rasmussen \& Bierman, 2016; Short, Kasper, \& Wetterneck, 2015; Wright, 2013; Wright, Bae, \& Funk, 2013) that has consistently found that religious people report less use of pornography. Even so, religious people still report IPU (Grubbs, Exline, et al., 2015; Grubbs, Sessoms, Wheeler, \& Volk, 2010; Nelson, Padilla-Walker, \& Carroll, 2010; Patterson \& Price, 2012; Perry, 2017b; Perry \& Hayward, 2017). Furthermore, analyses of indirect indicators (e.g., search engine terms, aggregate Internet meta-data) have found that locales with higher religiousness may actually demonstrate greater IPU (Edelman, 2009; MacInnis \& Hodson, 2015; Whitehead \& Perry, 2017). As such, with regards to religion specifically, there seems to be evidence that a large number of people who report disapproval of pornography are actually engaging in IPU.

By definition, the contrast between religious individuals' reported moral disapproval of pornography and their reported use rates suggests that many religious people are likely experiencing some moral incongruence around their actions. This supposition is also supported by a body of literature suggesting that, in general, religiousness is associated with incongruence between sexual values and behaviors, even when objective behaviors are held constant (Hook, Farrell, Ramos, et al., 2015). More succinctly, religious people tend to think that their sexual behaviors are incongruent with their values, regardless of what those behaviors may actually be. Collectively, these findings suggest that religious individuals may often be experiencing incongruence about their pornography use. 


\section{Moral Incongruence}

At a theoretical level alone, moral incongruence regarding IPU warrants special consideration. However, there is evidence that this incongruence may also be meaningfully related to distressing experiences known to be associated with pornography use.

\section{Moral Incongruence and Psychological Distress}

By nature, incongruence between sexual values and sexual behavior is likely to be distressing. Humans desire to reduce cognitive dissonance whenever possible, and experiencing such discrepancy between one's purported values and actual behaviors is likely to promote distress. Importantly, this association is more than just theoretical. In a longitudinal, nationallyrepresentative panel study (Perry, 2017c), viewing pornography was associated with greater experience of depressive symptoms over a six-year period, but only among men who also morally disapproved of pornography use. More succinctly, pornography users who reported moral incongruence regarding their use were prone to experience more depression over time, suggesting that moral incongruence itself may play a meaningful role in the experience of psychological distress symptoms. Moral incongruence may also help explain intimate relational distress related to pornography use. Using the same representative panel data, Perry (In Press) also found that, for married pornography users who morally disapproved of pornography, their marital quality over a six-year period declined as their viewing frequency increased. Importantly, this was not the case for married pornography users who did not disapprove of pornography; their viewing frequency was unassociated with their marital quality over time.

Moving beyond moral incongruence specifically, there is also a large body of research now suggesting that religious individuals who use pornography—for whom moral incongruence is likely implied - also report a diverse range of distressing symptoms associated with their use. 
Religious pornography users report experiencing greater levels of depression in daily life (Nelson et al., 2010), lower levels of subjective happiness (Patterson \& Price, 2012) and sexual satisfaction (Perry \& Whitehead, 2018), greater levels of relational distress (Leonhardt, Willoughby, \& Young-Petersen, 2017; Perry, 2016), poorer quality in family relationships (Doran \& Price, 2014; Perry, 2016; Perry \& Snawder, 2017), and, as we explore below, greater levels of perceived addiction to pornography.

\section{Moral Incongruence and Perceived Addiction}

The role of moral incongruence in predicting meaningful experiences associated with IPU also bears direct implications for the debates around Internet pornography addiction. As previously alluded to, whether or not IPU is potentially addictive is a highly contentious subject. Despite these controversies, people often self-identify as addicted to pornography, even when the mental health and psychiatric communities have not officially recognized this diagnosis (Cavaglion, 2008; Grubbs et al., 2010). Flowing from this discrepancy, there has recently been a burgeoning focus on perceived addiction to Internet pornography (Blais-Lecours, VaillancourtMorel, Sabourin, \& Godbout, 2016; Bőthe, Tóth-Király, \& Orosz, 2014; Fernandez, Tee, \& Fernandez, 2017; Grubbs, Exline, et al., 2015; Leonhardt et al., 2017; Vaillancourt-Morel et al., 2017).

Perceived addiction to Internet pornography refers to the propensity of individuals to report feeling addicted or compulsive in their behaviors, regardless of the veracity of this selfperception (Grubbs, Volk, Exline, \& Pargament, 2015). As has been articulated in prior literature (Grubbs, Volk, et al., 2015; Wilt, Cooper, Grubbs, Exline, \& Pargament, 2016), perceived addiction to Internet pornography consists of three components: 1) cognitive appraisals of one's IPU (e.g., perceived dysregulation or compulsivity), 2) perceptions of one's behavioral 
engagement in pornography use (i.e., perceived disruption or access efforts), and 3)

psychological distress regarding one's IPU (i.e., perceived emotional distress). Although perceived addiction to Internet pornography is likely distinct from truly dysregulated IPU (Grubbs, Stauner, Exline, Pargament, \& Lindberg, 2015; Vaillancourt-Morel et al., 2017), it is still associated with a wide range of concerning psychological phenomena. Perceived addiction is associated with greater reported levels of psychological distress both concurrently (Grubbs, Exline, et al., 2015; Grubbs, Stauner, et al., 2015) and over time (Grubbs, Stauner, et al., 2015), with greater levels of alcohol use (Morelli, Bianchi, Baiocco, Pezzuti, \& Chirumbolo, 2017), with problematic gaming (Bőthe et al., 2014), with greater relational anxiety and distress (Leonhardt et al., 2017), with lower levels of reported sexual satisfaction and well-being (BlaisLecours et al., 2016; Vaillancourt-Morel et al., 2017), and with difficulties in one's religious and spiritual life (Grubbs, Exline, Pargament, Volk, \& Lindberg, 2017; Wilt et al., 2016). In short, perceived addiction is robustly related to a wide range of psychological and relational concerns that are likely to have profound influences on overall well-being.

In one of the first specific examinations of the relationships between perceived addiction and moral incongruence about IPU (measured as moral disapproval of IPU among pornography users), moral incongruence was consistently, positively related to greater levels of perceived addiction (Grubbs, Exline, et al., 2015). Specifically, in a sample of undergraduates at a religiously affiliated university ( $N=97, M_{\text {age }}=19.5, S D=1.3 ; 51 \%$ men) and a sample of undergraduates from two non-religiously affiliated universities $\left(\mathrm{N}=331, M_{\text {age }}=19.5, S D=1.9\right.$; $69 \%$ men), moral incongruence predicted perceived addiction above and beyond IPU itself. Furthermore, in subsequent analyses of a sample of adults $\left(N=208, M_{\text {age }}=31.8, \mathrm{SD}=10.6 ; 65 \%\right.$ men), moral incongruence again emerged as the chief predictor of perceived addiction. These 
findings persisted when IPU was held constant, suggesting that moral disapproval predicted perceived addiction above and beyond actual use of pornography. Finally, these relationships also persisted even when the emotional components of perceived addiction were removed, suggesting that moral incongruence's relationship with perceived addiction was not simply a function of emotional distress, but also involved perception of cognitive and behavioral components.

In a large scale analysis (Wilt et al., 2016) of undergraduates at three universities in the U.S. (N=1,070, $M_{\text {age }}=19.23, \mathrm{SD}=2.34 ; 68 \%$ men), moral incongruence (measured as moral disapproval of IPU among pornography users) was associated with perceived addiction. Specifically, raw correlations between moral incongruence and cognitive (perceptions of compulsivity; $r=.45$ ), behavioral (perceived behavioral disruption; $r=.27$ ), and emotional (perceived distress flowing from IPU; $r=.80$ ) components of perceived addiction were observed, with links between moral incongruence and both cognitive (partial $r=.14$ ) and emotional (partial $r=.67$ ) components of perceived addiction persisting, even when IPU itself and all other facets of perceived addiction (e.g., moral incongruence and cognitive components, controlling for emotional and behavioral components) were held constant. Collectively, such findings point toward compelling and robust relationships between moral incongruence and the experience of perceived addiction.

These findings also appear to persist over time (Grubbs, Wilt, Exline, Pargament, \& Kraus, 2017). Specifically, in two longitudinal samples, one of undergraduates ( $N=146$, $M_{\text {age }}=19.3, \mathrm{SD}=2.2 ; 67 \%$ men) and one of adults ( $=211, M_{\text {age }}=32.6, \mathrm{SD}=10.3 ; 73.5 \%$ men), baseline levels of moral incongruence around IPU (measured as moral disapproval of IPU among pornography users) maintained strong, positive relationships with perceived addiction even a 
year later (Sample 1, undergraduates, $r=.46$; Sample 2, adult web-users, $r=.61$ ). In regression analyses, when baseline levels of perceived addiction were held constant, the links between moral incongruence and perceived addiction were reduced to non-significance. However, given the raw associations over time and the strong cross-sectional associations between baseline moral incongruence and baseline perceived addiction (Sample 1, undergraduates $r=.68$; Sample 2, adult web-users, $r=.58$ ), these associations seem to indicate that moral incongruence is a key facet of perceived addiction.

Additionally, in a sample of young adult men in Malaysia $\left(\mathrm{N}=76, M_{a g e}=22.3, \mathrm{SD}=3.4\right.$; $100 \%$ men), substantive, positive correlations between moral incongruence regarding IPU (measured as moral disapproval of IPU among pornography users) and perceived addiction $(r=.41)$ were consistently observed (Fernandez et al., 2017). When examined at a component level (i.e., emotional aspects of perceived addiction vs. cognitive aspects), these relationships were strongest for feelings of emotional distress around IPU $(r=.41)$, but were also observed for reports of compulsivity as well $(r=.23)$. Importantly, moral incongruence about IPU was not significantly associated with failed attempts to regulate IPU or efforts to regulate use, suggesting that moral incongruence likely contributes to cognitive and emotional aspects of perceived addiction, rather than to actual dysregulated behaviors. Finally, these findings are notable, as this sample was not a majority Christian or Caucasian, as previously reviewed samples were, with the most common religious affiliation reported being Buddhist (35.5\%) and the most common ethnic origin being Chinese $(80.3 \%)$.

Moving beyond direct measures of moral incongruence, there is again compelling evidence that religiousness among pornography users is also a driving factor in the experience of perceived addiction. In very early work on this topic (Abell, Steenbergh, \& Boivin, 2006) using a 
sample of undergraduates $\left(\mathrm{N}=125, M_{\text {age }}=20.7, \mathrm{SD}=4.5 ; 100 \%\right.$ men $)$, religious commitment was associated with greater reported feelings of compulsivity related to pornography use. This data was also supported by early qualitative works noting that young men in Christian universities were particularly prone to interpret IPU and masturbation as pathological or even addictive processes, even when their objective behaviors fell within normal limits (Kwee, Dominguez, \& Ferrell, 2007). Furthermore, comparisons of samples of undergraduates from non-religiously affiliated $\left(\mathrm{N}=145 ; M_{\text {age }}=\mathrm{NA} ; 65 \%\right.$ men $)$ and religiously affiliated $\left(\mathrm{N}=127 ; M_{\text {age }}=\mathrm{NA} ; 80 \%\right.$ men $)$ universities have found that students at a religious university consistently report less use of pornography but greater feelings of perceived addiction (Sessoms, 2011).

These findings have also persisted into more recent analyses (Volk, Thomas, Sosin, Jacob, \& Moen, 2016) of adults in the U.S. $\left(N=358, M_{a g e}=34.1 ; \mathrm{SD}=10.6 ; 52 \%\right.$ men $)$, both religiousness $(r=.19)$ and sexual shame $(r=.36)$ were found to be positively associated with perceived addiction. Additionally, in a very recent analysis (Leonhardt et al., 2017) of a sample of adult web-users in the U.S. $\left(N=686, M_{a g e}=28.5 ; S D=7.9 ; 51 \%\right.$ men $)$, religiousness was again found to be positively associated with perceived addiction $(r=.297)$.

These findings are also evident in comparisons of religious believers and non-believers on measures of perceived addiction (Bradley, Grubbs, Uzdavines, Exline, \& Pargament, 2016). Specifically, in a sample of adults $\left(\mathrm{N}=713, M_{a g e}=30.2, \mathrm{SD}=9.9 ; 52 \%\right.$ men $)$, identification with any religion - as opposed to identifying as an atheist, agnostic, or religious "none" —was a consistent positive predictor of perceived addiction. Notably, these findings persisted, even when gender, age, socially-desirable response biases, and actual use of pornography were held constant. 
These findings also seem to persist in clinical samples. Among a group of men seeking treatment for problematic IPU in Poland $\left(\mathrm{N}=132, M_{a g e}=28.7, \mathrm{SD}=6.4 ; 100 \%\right.$ men; Gola et al., 2016), both IPU itself and religiousness uniquely predicted feelings of addiction or compulsivity in their usage. More specifically, self-perceived pornography addiction (indicated by a measure of preoccupation and perceived loss of control) was uniquely and comparably predicted by both IPU itself and reported levels of religiosity, indicating that, even in a clinical sample, moral incongruence likely plays a key role in perceived addiction.

Finally, it is also noteworthy that these findings extend beyond the realm of IPU alone, and may also apply to sexuality more broadly. A number of studies (Griffin et al., 2016; Hook, Farrell, Davis, et al., 2015; Hook, Farrell, Ramos, et al., 2015) have also found links between moral incongruence and self-reported feelings of hypersexuality in general, which is not restricted to pornography use alone (Reid, Garos, \& Carpenter, 2011). Collectively, these findings suggest that moral incongruence is likely a key factor in predicting perceived addiction, which is particularly concerning, given the known links between perceived addiction and a wide range of problematic psychological phenomena. Therefore, as has been argued elsewhere (Grubbs, Stauner, et al., 2015), perceived addiction to Internet pornography is a clinical concern, and given that moral incongruence about IPU predicts this phenomenon so well, it is likely that such incongruence is a clinical concern within itself.

\section{Discussion and Implications}

Collectively, through a brief review of literature, we have examined a few key themes: 1) there is considerable evidence that many individuals, particularly religious individuals, strongly disapprove of IPU while still using it, 2) moral incongruence around IPU is associated with a number of negative experiences such as greater reports of depression, distress, and relational 
problems, and 3) moral incongruence may be a driving factor in the experience of self-perceived pornography addiction or even sexual addiction more broadly. Below, we seek to discuss the implications of these key findings and propose directions for future research.

Clearly, some people may find their IPU problematic for a host of reasons, including true dysregulation, relational conflict, or even legal concerns. However, the results of the present review indicate that moral incongruence around IPU may also be another avenue by which such self-perceptions may arise. From a research perspective, there is a clear need to better account for the many ways by which one may come to identify as addicted to Internet pornography. As the present review suggests, those self-diagnoses may not always reflect severe dysregulation or compulsivity. However, they almost invariably do represent an important threat to mental health, relational functioning, and general well-being. These alternate ways by which IPU may be interpreted as problematic are in dire need of careful future consideration. The research in this domain is still burgeoning, with all papers reviewed herein having been published in the past 10 years, with two exceptions (Abell et al., 2006; Kwee et al., 2007). As such, there is a clear and present need for further empirical studies of the many pathways by which pornography users may report developing or experiencing problems.

More specifically, our review also implies_ - as others have also suggested (Humphreys, 2017; Williams, 2017) — that porported pornography and sexual addictions are unique in the total domain of behavioral addictions. Whereas all addictions often imply distress, dysfunction, and dysregulation, we are unaware of any other addiction for which personal morality and moral incongruence seem to play such meaningful roles in predicting self-perceptions of problems or compulsivity. More to the point, to the extent that IPU is thought of as an addiction, it is clear that this purported addiction is functioning differently than other addictions typically do. 
Similarly, the findings of the present review are of particular note, given clinical research indicating that frequency of use and time spent viewing pornography are not related to seeking professional help for pornography addiction (Gola et al., 2016; Kraus et al., 2016). More succinctly, regarding pornography use specifically, a body of evidence now suggests that moral incongruence is at least as important as objective behaviors in predicting who believes themselves to be addicted.

In clinical settings, our findings suggest that understanding the full etiology of a client's self-identified pornography addiction is likely an important venture. Although we would hope that such holistic considerations are natural to most therapists, there is some evidence of variability in how therapists approach sexual issues. For example, past research has found that more religious therapists are more likely to diagnose sexual addiction (Hecker, Trepper, Wetchler, \& Fontaine, 1995) in clientele presenting with what reports of excessive sexual behaviors. Similarly, more religious therapists are more likely to label online sexual activity an addiction (Hertlein \& Piercy, 2008). In short, therapist religiousness and morality seem to influence how clients' sexual behaviors are interpreted. This is particularly concerning, given that perceived moral judgments from clinicians may reduce client willingness to continue in therapy (Harris \& Darby, 2009). As such, given the findings of the present work, thoroughness and caution are imperative.

Importantly, however, our findings do not imply that moral incongruence, perceived addiction to Internet pornography, or general distress regarding pornography use should be arbitrarily dismissed as an artifact of religiously or morally-based scruples around sexuality or pornography use. On the contrary, the findings of the present review suggest that IPU may be especially problematic for religious individuals or those individuals who generally morally 
disapprove of pornography use. For these people, objective dysregulation might not be the only pathway by which their behaviors may lead to distress or dysfunction. In clinical and applied settings, the implications of the present review are of key importance. As previously reviewed, increasing numbers of psychiatrists (Gola \& Potenza, 2016; Kraus et al., 2015) and mental health professionals more broadly (Kalman, 2008; Short et al., 2016) report encountering problematic IPU in clinical practice. Although many of these encounters represent truly dysregulated behavior patterns (Kraus et al., 2015), given the lack of diagnostic and assessment clarity about problematic IPU, it is unclear what percentage of individuals seeking treatment for problematic IPU are actually experiencing dysregulated behaviors and what percentage may also be experiencing profound distress and difficulty secondary to moral incongruence. Given that, in samples of men seeking treatment for problematic IPU (Gola et al., 2016), religiousness (which implies moral incongruence) was as robust a predictor of IPU-related problems as average weekly IPU itself was, it is likely that substantial proportions of individuals seeking clinical help for self-perceived problematic IPU may be experiencing distress as a function of moral incongruence. Collectively, the present work suggests that clinicians who encounter such clientele should be curious about and open to the role of moral incongruence in the clinical presentation of problematic pornography use.

\section{Limitations and Future Directions}

Despite the growing body of literature in this domain, there are still several clear issues with present research related to pornography use, addiction, and the roles of morality and moral incongruence. Chief among these issues is the ongoing debate about the addictive or nonaddictive nature of pornography. Although the literature discussed herein is meant to contribute meaningfully to this debate, the lack of consensus within the field has provided clear obstacles to 
forming cohesive research programs examining how things such as religiousness and moral incongruence may relate to pornography addiction (or non-addiction).

Additionally, the majority of the research reviewed in the present work was crosssectional or nominally longitudinal (e.g., only two time points). Such designs prevent clear causal inferences. As such, there is a pressing need for future studies using multiple-time point (e.g., more than 3 time points) designs, as well as experimental studies. Experimental designs might seek to establish the role of religiousness in driving moral disapproval of pornography (e.g., religious priming exercises) or how perceptions of moral incongruence influence observer interpretations of behavior (e.g., scenario or vignette studies).

Regarding religiousness, as was alluded to in an earlier footnote, the majority of research related to pornography use has not examined religious variables with great nuance. Authoritarian religious tendencies (Levert, 2007) or religiously based scruples (Abramowitz, Huppert, Cohen, Tolin, \& Cahill, 2002; Short et al., 2015) may certainly impact one's views of one's own pornography use, promoting greater guilt, shame, or incongruence. Additionally, religion often involves both personal and social components (e.g., community involvement or family relationships). It is likely that social and relational aspects of religion may impact how individuals experience their own pornography use. Indeed, some research suggests that familial religiousness does impact personal use of pornography (Perry, 2016, 2017d; Rasmussen \& Bierman, 2017). Collectively, these types of nuances around religiousness more broadly suggest that there is a greater need for research specifically examining the aspects of religiousness (both intrapersonally and interpersonally) that are likely to promote greater feelings of moral incongruence around pornography use. 
We would additionally note that the current state of the literature does not allow for definitive causal inferences regarding the interplay of religiousness and pornography use as it relates to psychological distress more broadly. Although evidence (both cross-sectionally and longitudinally) supports the conclusion that religious individuals are less likely to view pornography and more likely to experience moral incongruence when they do, evidence of psychological distress among religious users of pornography (e.g., (Nelson et al., 2010; Patterson $\&$ Price, 2012) is largely cross-sectional in nature. At least in premise, this leaves open the possibility that religious people who are more generally psychologically distressed are also more likely to use pornography. Even so, there is both cross-sectional and longitudinal evidence that moral incongruence and its close associate--perceived addiction-are related to greater experiences of psychological distress. As such, we would contend that the most reasonable hypothesis regarding religious users of pornography and psychological distress is that such use promotes distress. This contention is in need of future research.

Finally, the present review has specifically focused on how pornography use and feelings of dysregulation or addiction may be influenced by religiousness and moral incongruence, with a focus on negative outcomes. However, it is at least plausible that pornography use itself may also influence religiousness and moral incongruence. Indeed, there is some research suggesting that pornography use may enhance religiousness (Perry, 2017a), threaten religious socialization (Perry, 2015; Perry \& Hayward, 2017), promote greater religious and spiritual difficulties (Griffin et al., 2016; Grubbs, Exline, et al., 2017; Wilt et al., 2016) and promote egalitarian or progressive attitudes among religious individuals (Rasmussen \& Kohut, 2017). These seemingly disparate findings suggest that there is a need for further inquiry into the reciprocal relationships between religiousness and pornography use that may extend beyond simple examinations of 
moral incongruence or perceived addiction. Furthermore, such findings suggest that the interactions between religiousness and pornography use may also have potential for positive or progressive outcomes as well (e.g., increased egalitarian attitudes; Rasmussen \& Kohut, 2017).

\section{Conclusions}

IPU is and will likely remain a morally charged issue, filled with contentious debate and opposing viewpoints. Within the scientific and mental-health communities at large, the morally charged nature of this topic cannot be ignored. Moral incongruence, in this case, the experience of disapproving of IPU while still using it, seems to be a key variable in predicting a host of important outcomes associated with pornography use, not the least of which is perceived addiction to Internet pornography. Collectively, these findings suggest that clinicians and researchers alike should be mindful of the role of moral incongruence in driving problematic experiences associated with IPU. Furthermore, future debate about the addictive (or nonaddictive) status of Internet pornography would be well-advised to seek to account for the role of moral incongruence in driving perceptions of addiction. 


\section{References}

Abell, J. W., Steenbergh, T. A., \& Boivin, M. J. (2006). Cyberporn use in the context of religiosity. Journal of Psychology and Theology, 34, 165.

Abramowitz, J. S., Huppert, J. D., Cohen, A. B., Tolin, D. F., \& Cahill, S. P. (2002). Religious obsessions and compulsions in a non-clinical sample: The Penn Inventory of Scrupulosity (PIOS). Behaviour Research and Therapy, 40, 825-838.

Barak, A., \& Fisher, W. A. (2002). The future of Internet sexuality. Sex and the Internet: A Guide Book for Clinicians, 267-280.

Blais-Lecours, S., Vaillancourt-Morel, M.-P., Sabourin, S., \& Godbout, N. (2016). Cyberpornography: Time use, perceived addiction, sexual functioning, and sexual satisfaction. Cyberpsychology, Behavior, and Social Networking, 19, 649-655. https://doi.org/10.1089/cyber.2016.0364

Bőthe, B., Tóth-Király, I., \& Orosz, G. (2014). Clarifying the links among online gaming, internet use, drinking motives, and online pornography use. Games for Health Journal, 4, 107-112. https://doi.org/10.1089/g4h.2014.0054

Boulton, C. (2008). Porn and me(n): Sexual morality, objectification, and religion at the wheelock anti-pornography conference. The Communication Review, 11, 247-273. https://doi.org/10.1080/10714420802306544

Bradley, D. F., Grubbs, J. B., Uzdavines, A., Exline, J. J., \& Pargament, K. I. (2016). Perceived addiction to internet pornography among religious believers and nonbelievers. Sexual Addiction \& Compulsivity, 23, 225-243. https://doi.org/10.1080/10720162.2016.1162237

Campbell, L., \& Kohut, T. (2017). The use and effects of pornography in romantic relationships. Current Opinion in Psychology, 13, 6-10. 
Cavaglion, G. (2008). Voices of coping in an Italian self-help virtual community of cyberporn dependents. CyberPsychology \& Behavior, 11, 599-601. https://doi.org/10.1089/cpb.2007.0204

Clarkson, J., \& Kopaczewski, S. (2013). Pornography addiction and the medicalization of free speech. Journal of Communication Inquiry, 37, 128-148. https://doi.org/10.1177/0196859913482330

Cooper, A. (1998). Sexuality and the Internet: Surfing into the new millennium. CyberPsychology \& Behavior, 1, 187-193. https://doi.org/10.1089/cpb.1998.1.187

Cooper, A., McLoughlin, I. P., \& Campbell, K. M. (2000). Sexuality in cyberspace: Update for the 21 st century. CyberPsychology \& Behavior, 3, 521-536. https://doi.org/10.1089/109493100420142

Delmonico, D. L., \& Carnes, P. J. (1999). Virtual sex addiction: When cybersex becomes the drug of choice. CyberPsychology \& Behavior, 2, 457-463. https://doi.org/10.1089/cpb.1999.2.457

Doran, K., \& Price, J. (2014). Pornography and marriage. Journal of Family and Economic Issues, 35, 489-498. https://doi.org/10.1007/s10834-014-9391-6

Driscoll, M. (2009). Porn-again christian: A frank discussion on pornography \& masturbation. Relit.org.

Duffy, A., Dawson, D. L., \& das Nair, R. (2016). Pornography addiction in adults: A systematic review of definitions and reported impact. The Journal of Sexual Medicine, 13, 760-777. https://doi.org/10.1016/j.jsxm.2016.03.002

Edelman, B. (2009). Red light states: Who buys online adult entertainment? The Journal of Economic Perspectives, 23, 209-220. 
Fernandez, D. P., Tee, E. Y. J., \& Fernandez, E. F. (2017). Do cyber pornography use inventory9 scores reflect actual compulsivity in internet pornography use? Exploring the role of abstinence effort. Sexual Addiction \& Compulsivity, 24, 156-179. https://doi.org/10.1080/10720162.2017.1344166

Fisher, W. A., \& Barak, A. (2001). Internet pornography: A social psychological perspective on internet sexuality. The Journal of Sex Research, 38, 312-323. https://doi.org/10.1080/00224490109552102

Foubert, J. D. (2016). How Pornography Harms: Today's Research, Scholarly Perspectives, and Real Life Stories. Taylor \& Francis.

Gmeiner, M., Price, J., \& Worley, M. (2015). A review of pornography use research: Methodology and results from four sources. Cyberpsychology: Journal of Psychosocial Research on Cyberspace, 9. https://doi.org/10.5817/CP2015-4-4

Gola, M., Lewczuk, K., \& Skorko, M. (2016). What matters: Quantity or quality of pornography use? Psychological and behavioral factors of seeking treatment for problematic pornography use. The Journal of Sexual Medicine, 13, 815-824. https://doi.org/10.1016/j.jsxm.2016.02.169

Gola, M., \& Potenza, M. N. (2016). Paroxetine treatment of problematic pornography use: A case series. Journal of Behavioral Addictions, 5, 529-532. https://doi.org/10.1556/2006.5.2016.046

Griffin, B. J., Worthington, E. L., Leach, J. D., Hook, J. N., Grubbs, J., Exline, J. J., \& Davis, D. E. (2016). Sexual congruence moderates the associations of hypersexual behavior with spiritual struggle and sexual self-concept. Sexual Addiction \& Compulsivity, 23, 279-295. https://doi.org/10.1080/10720162.2016.1150924 
Griffiths, M. (2000). Excessive Internet use: Implications for sexual behavior. CyberPsychology \& Behavior, 3, 537-552.

Griffiths, M. (2001). Sex on the internet: Observations and implications for internet sex addiction. Journal of Sex Research, 38, 333-342.

Grubbs, J. B., Exline, J. J., Pargament, K. I., Hook, J. N., \& Carlisle, R. D. (2015). Transgression as addiction: Religiosity and moral disapproval as predictors of perceived addiction to pornography. Archives of Sexual Behavior, 44, 125-136. https://doi.org/10.1007/s10508$013-0257-z$

Grubbs, J. B., Exline, J. J., Pargament, K. I., Volk, F., \& Lindberg, M. J. (2017). Internet pornography use, perceived addiction, and religious/spiritual struggles. Archives of Sexual Behavior, 46, 1733-1745. https://doi.org/10.1007/s10508-016-0772-9

Grubbs, J. B., Sessoms, J., Wheeler, D. M., \& Volk, F. (2010). The Cyber-Pornography Use Inventory: The development of a new assessment instrument. Sexual Addiction \& Compulsivity, 17, 106-126. https://doi.org/10.1080/10720161003776166

Grubbs, J. B., Stauner, N., Exline, J. J., Pargament, K. I., \& Lindberg, M. J. (2015). Perceived addiction to Internet pornography and psychological distress: Examining relationships concurrently and over time. Psychology of Addictive Behaviors, 29, 1056.

Grubbs, J. B., Volk, F., Exline, J. J., \& Pargament, K. I. (2015). Internet pornography use: Perceived addiction, psychological distress, and the validation of a brief measure. Journal of Sex \& Marital Therapy, 41, 83-106. https://doi.org/10.1080/0092623X.2013.842192

Grubbs, J. B., Wilt, J. A., Exline, J. J., Pargament, K. I., \& Kraus, S. W. (2017). Moral disapproval and perceived addiction to internet pornography: A longitudinal examination. Addiction, n/a-n/a. https://doi.org/10.1111/add.14007 
Hardy, S. A., Steelman, M. A., Coyne, S. M., \& Ridge, R. D. (2013). Adolescent religiousness as a protective factor against pornography use. Journal of Applied Developmental Psychology, 34, 131-139. https://doi.org/10.1016/j.appdev.2012.12.002

Harris, C. R., \& Darby, R. S. (2009). Shame in physician-patient interactions: Patient perspectives. Basic and Applied Social Psychology, 31, 325-334. https://doi.org/10.1080/01973530903316922

Hecker, L. L., Trepper, T. S., Wetchler, J. L., \& Fontaine, K. L. (1995). The influence of therapist values, religiosity and gender in the initial assessment of sexual addiction by family therapists. The American Journal of Family Therapy, 23, 261-272. https://doi.org/10.1080/01926189508251356

Hertlein, K. M., \& Piercy, F. P. (2008). Therapists' assessment and treatment of Internet infidelity cases. Journal of Marital and Family Therapy, 34, 481-497.

Hill, P. C., Pargament, K. I., Hood, R. W., McCullough Jr, M. E., Swyers, J. P., Larson, D. B., \& Zinnbauer, B. J. (2000). Conceptualizing religion and spirituality: Points of commonality, points of departure. Journal for the Theory of Social Behaviour, 30, 51-77.

Hill, P., \& Pargament, K. (2003). Advances in the conceptualization and measurement of religion and spirituality. Implications for physical and mental health research. The American Psychologist, 58, 64-74.

Hook, J. N., Farrell, J. E., Davis, D. E., Tongeren, D. R. V., Griffin, B. J., Grubbs, J., ... Bedics, J. D. (2015). Self-forgiveness and hypersexual behavior. Sexual Addiction \& Compulsivity, 22, 59-70. https://doi.org/10.1080/10720162.2014.1001542 
Hook, J. N., Farrell, J. E., Ramos, M. J., Davis, D. E., Karaga, S., Tongeren, D. R. V., \& Grubbs, J. (2015). Religiousness and congruence between sexual values and behavior. Journal of Psychology and Christianity, 34, 179-189.

Humphreys, K. (2017). Of moral judgments and sexual addictions. Addiction.

Johnson, P. (1996). Pornography drives technology: Why not to censor the Internet. Fed. Comm. $L J, 49,217$.

Kalman, T. P. (2008). Clinical encounters with Internet pornography. Journal of the American Academy of Psychoanalysis and Dynamic Psychiatry, 36, 593-618.

Kohut, T., Baer, J. L., \& Watts, B. (2016). Is pornography really about “making hate to women”? Pornography users hold more gender egalitarian attitudes than nonusers in a representative American sample. The Journal of Sex Research, 53, 1-11.

Kohut, T., Fisher, W. A., \& Campbell, L. (2017). Perceived effects of pornography on the couple relationship: Initial findings of open-ended, participant-informed, "bottom-up" research. Archives of Sexual Behavior, 46, 585-602. https://doi.org/10.1007/s10508-016-0783-6

Kor, A., Zilcha-Mano, S., Fogel, Y. A., Mikulincer, M., Reid, R. C., \& Potenza, M. N. (2014). Psychometric development of the Problematic Pornography Use Scale. Addictive Behaviors, 39, 861-868. https://doi.org/10.1016/j.addbeh.2014.01.027

Kraus, S. W., Martino, S., \& Potenza, M. N. (2016). Clinical characteristics of men interested in seeking treatment for use of pornography. Journal of Behavioral Addictions, 5, 169-178. https://doi.org/10.1556/2006.5.2016.036

Kraus, S. W., Meshberg-Cohen, S., Martino, S., Quinones, L. J., \& Potenza, M. N. (2015). Treatment of compulsive pornography use with naltrexone: A case report. American Journal of Psychiatry, 172, 1260-1261. https://doi.org/10.1176/appi.ajp.2015.15060843 
Kwee, W. A., Dominguez, A. W., \& Ferrell, D. (2007). Sexual addiction and Christian college men: Conceptual, assessment, and treatment challenges. J Psychol Christ, 26, 3-13.

Lambe, J. L. (2004). Who wants to censor pornography and hate speech? Mass Communication and Society, 7, 279-299. https://doi.org/10.1207/s15327825mcs0703_2

Leonhardt, N. D., Willoughby, B. J., \& Young-Petersen, B. (2017). Damaged goods: Perception of pornography addiction as a mediator between religiosity and relationship anxiety surrounding pornography use. The Journal of Sex Research, 0, 1-12. https://doi.org/10.1080/00224499.2017.1295013

Levert, N. P. (2007). A comparison of Christian and non-Christian males, authoritarianism, and their relationship to internet pornography addiction/compulsion. Sexual Addiction \& Compulsivity, 14, 145-166.

Ley, D. J. (2016). Ethical porn for dicks: A man's guide to responsible viewing pleasure. ThreeL Media.

Ley, D. J., \& Grubbs, J. B. (2017). The Sexhavior Cycle: Good review, but still not enough data to support a new theory. Archives of Sexual Behavior. https://doi.org/10.1007/s10508017-1067-5

Ley, D. J., Prause, N., \& Finn, P. (2014). The emperor has no clothes: A review of the ‘pornography addiction' model. Current Sexual Health Reports, 6, 94-105. https://doi.org/10.1007/s11930-014-0016-8

Lykke, L. C., \& Cohen, P. N. (2015). The widening gender gap in opposition to pornography, 1975-2012. Social Currents, 2, 307-323. 
MacInnis, C. C., \& Hodson, G. (2015). Do American states with more religious or conservative populations search more for sexual content on google? Archives of Sexual Behavior, 44, 137-147. https://doi.org/10.1007/s10508-014-0361-8

MacInnis, C. C., \& Hodson, G. (2016). Surfing for sexual sin: Relations between religiousness and viewing sexual content online. Sexual Addiction \& Compulsivity, 23, 196-210. https://doi.org/10.1080/10720162.2015.1130000

Montgomery-Graham, S., Kohut, T., Fisher, W., \& Campbell, L. (2015). How the popular media rushes to judgment about pornography and relationships while research lags behind. The Canadian Journal of Human Sexuality, 24, 243-256.

Morelli, M., Bianchi, D., Baiocco, R., Pezzuti, L., \& Chirumbolo, A. (2017). Sexting behaviors and cyber pornography addiction among adolescents: The moderating role of alcohol consumption. Sexuality Research and Social Policy, 14, 113-121. https://doi.org/10.1007/s13178-016-0234-0

Mura, D. (1985). A Male Grief: Notes on Pornography and Addiction: an Essay. Milkweed Editions.

Nelson, L. J., Padilla-Walker, L. M., \& Carroll, J. S. (2010). "I believe it is wrong but I still do it”: A comparison of religious young men who do versus do not use pornography. Psychology of Religion and Spirituality, 2, 136-147. https://doi.org/10.1037/a0019127

Ogas, O., \& Gaddam, S. (2011). A Billion Wicked Thoughts: What the Internet Tells Us about Sexual Relationships. PLUME.

Oman, D. (2013). Defining religion and spirituality. Handbook of the Psychology of Religion and Spirituality, 2, 23-47. 
Pargament, K. I. (1999). The psychology of religion and spirituality? Yes and no. The International Journal for the Psychology of Religion, 9, 3-16.

Patterson, R., \& Price, J. (2012). Pornography, religion, and the happiness gap: Does pornography impact the actively religious differently? Journal for the Scientific Study of Religion, 51, 79-89.

Perry, S. L. (In Press). Pornography use and marital quality: Testing the moral incongruence hypothesis. Personal Relationships. https://doi.org/10.17605/OSF.IO/XM2TP

Perry, S. L. (2015). Pornography consumption as a threat to religious socialization. Sociology of Religion, 76, 436-458. https://doi.org/10.1093/socrel/srv043

Perry, S. L. (2016). From bad to worse? Pornography consumption, spousal religiosity, gender, and marital quality (Vol. 31, pp. 441-464). Presented at the Sociological Forum, Wiley Online Library.

Perry, S. L. (2017a). Does viewing pornography diminish religiosity over time? Evidence from two-wave panel data. The Journal of Sex Research, 54, 214-226. https://doi.org/10.1080/00224499.2016.1146203

Perry, S. L. (2017b). Not practicing what you preach: Religion and incongruence between pornography beliefs and usage. The Journal of Sex Research, 0, 1-12. https://doi.org/10.1080/00224499.2017.1333569

Perry, S. L. (2017c). Pornography use and depressive symptoms: Examining the role of moral incongruence. Society and Mental Health, 2156869317728373. https://doi.org/10.1177/2156869317728373

Perry, S. L. (2017d). Spousal religiosity, religious bonding, and pornography consumption. Archives of Sexual Behavior, 46, 561-574. https://doi.org/10.1007/s10508-016-0896-y 
Perry, S. L., \& Hayward, G. M. (2017). Seeing is (Not) Believing: How Viewing Pornography Shapes the Religious Lives of Young Americans. Social Forces, 95, 1757-1788. https://doi.org/10.1093/sf/sow106

Perry, S. L., \& Snawder, K. J. (2017). Pornography, religion, and parent-child relationship quality. Archives of Sexual Behavior, 46, 1747-1761. https://doi.org/10.1007/s10508016-0927-8

Perry, S. L., \& Whitehead, A. L. (2018). Only bad for believers? Religion, pornography use, and sexual satisfaction among American men. Journal of Sex Research. https://doi.org/10.1080/00224499.2017.1423017

Rasmussen, K. R., \& Bierman, A. (2016). How does religious attendance shape trajectories of pornography use across adolescence? Journal of Adolescence, 49, 191-203.

Rasmussen, K. R., \& Bierman, A. (2017). Religious and Community Hurdles to Pornography Consumption: A National Study of Emerging Adults. Emerging Adulthood, 2167696817702066 .

Rasmussen, K. R., \& Kohut, T. (2017). Does religious attendance moderate the connection between pornography consumption and attitudes toward women? The Journal of Sex Research. Retrieved from http://www.tandfonline.com/doi/abs/10.1080/00224499.2017.1396571

Regnerus, M., Gordon, D., \& Price, J. (2016). Documenting pornography use in America: a comparative analysis of methodological approaches. The Journal of Sex Research, 53, 873-881.

Reid, R. C., Garos, S., \& Carpenter, B. N. (2011). Reliability, validity, and psychometric development of the Hypersexual Behavior Inventory in an outpatient sample of men. 
Sexual Addiction \& Compulsivity, 18, 30-51.

https://doi.org/10.1080/10720162.2011.555709

Rissel, C., Richters, J., Visser, R. O. de, McKee, A., Yeung, A., \& Caruana, T. (2017). A profile of pornography users in australia: Findings from the second australian study of health and relationships. The Journal of Sex Research, 54, 227-240.

https://doi.org/10.1080/00224499.2016.1191597

Robison, J. (1982). Pornography, the polluting of America. Tyndale House Publishers.

Rogala, C., \& Tydén, T. (2003). Does pornography influence young women's sexual behavior? Women's Health Issues, 13, 39-43. https://doi.org/10.1016/S1049-3867(02)00174-3

Ross, M. W., Månsson, S.-A., \& Daneback, K. (2012). Prevalence, severity, and correlates of problematic sexual internet use in Swedish men and women. Archives of Sexual Behavior, 41, 459-466. https://doi.org/10.1007/s10508-011-9762-0

Sessoms, J. (2011). The cyber pornography use inventory: Comparing a religious and secular sample. Retrieved from http://digitalcommons.liberty.edu/honors/247/

Sherkat, D. E., \& Ellison, C. G. (1997). The cognitive structure of a moral crusade: Conservative Protestantism and opposition to pornography. Social Forces, 75, 957-980. https://doi.org/10.1093/sf/75.3.957

Short, M. B., Kasper, T. E., \& Wetterneck, C. T. (2015). The relationship between religiosity and internet pornography use. Journal of Religion and Health, 54, 571-583. https://doi.org/10.1007/s10943-014-9849-8

Short, M. B., Wetterneck, C. T., Bistricky, S. L., Shutter, T., \& Chase, T. E. (2016). Clinicians' beliefs, observations, and treatment effectiveness regarding clients' sexual addiction and 
internet pornography use. Community Mental Health Journal, 52, 1070-1081.

https://doi.org/10.1007/s10597-016-0034-2

Svedin, C. G., Åkerman, I., \& Priebe, G. (2011). Frequent users of pornography. A population based epidemiological study of Swedish male adolescents. Journal of Adolescence, 34, 779-788. https://doi.org/10.1016/j.adolescence.2010.04.010

Thomas, J. N. (2013). Outsourcing moral authority: The internal secularization of evangelicals' anti-pornography narratives. Journal for the Scientific Study of Religion, 52. https://doi.org/10.1111/jssr.12052

Thomas, J. N. (2016). The development and deployment of the idea of pornography addiction within American Evangelicalism. Sexual Addiction \& Compulsivity, 23, 182-195. https://doi.org/10.1080/10720162.2016.1140603

United States Attorney General's Commission. (1986). Attorney General's Commission on Pornography: Final Report. U.S. Department of Justice.

Vaillancourt-Morel, M.-P., Blais-Lecours, S., Labadie, C., Bergeron, S., Sabourin, S., \& Godbout, N. (2017). Profiles of cyberpornography use and sexual well-being in adults. The Journal of Sexual Medicine, 14, 78-85. https://doi.org/10.1016/j.jsxm.2016.10.016

Volk, F., Thomas, J., Sosin, L., Jacob, V., \& Moen, C. (2016). Religiosity, developmental context, and sexual shame in pornography users: A serial mediation model. Sexual Addiction \& Compulsivity, 23, 244-259. https://doi.org/10.1080/10720162.2016.1151391

Walton, M. T., Cantor, J. M., Bhullar, N., \& Lykins, A. D. (2017). Hypersexuality: A critical review and introduction to the "Sexhavior Cycle." Archives of Sexual Behavior, 1-21. https://doi.org/10.1007/s10508-017-0991-8 
Weinberg, M. S., Williams, C. J., Kleiner, S., \& Irizarry, Y. (2010). Pornography, normalization, and empowerment. Archives of Sexual Behavior, 39, 1389-1401. https://doi.org/10.1007/s10508-009-9592-5

Whitehead, A. L., \& Perry, S. L. (2017). Unbuckling the Bible belt: A state-level analysis of religious factors and google searches for porn. The Journal of Sex Research, 0, 1-11. https://doi.org/10.1080/00224499.2017.1278736

Williams, D. J. (2017). The framing of frequent sexual behavior and/or pornography viewing as addiction: Some concerns for social work. Journal of Social Work, 17, 616-623. https://doi.org/10.1177/1468017316644701

Wilt, J. A., Cooper, E. B., Grubbs, J. B., Exline, J. J., \& Pargament, K. I. (2016). Associations of perceived addiction to internet pornography with religious/spiritual and psychological functioning. Sexual Addiction \& Compulsivity, 23, 260-278. https://doi.org/10.1080/10720162.2016.1140604

Wright, P. J. (2013). U.S. males and pornography, 1973-2010: Consumption, predictors, correlates. The Journal of Sex Research, 50, 60-71. https://doi.org/10.1080/00224499.2011.628132

Wright, P. J., Bae, S., \& Funk, M. (2013). United States women and pornography through four decades: Exposure, attitudes, behaviors, individual differences. Archives of Sexual Behavior, 42, 1131-1144. https://doi.org/10.1007/s10508-013-0116-y

Young, K. S. (2008). Internet sex addiction: Risk factors, stages of development, and treatment. American Behavioral Scientist, 52, 21-37. 